\title{
Experimental Investigation on Effect of Partial Replacement of Cement with Bamboo Leaf Ash on Concrete Property
}

\author{
Gashaw Abebaw (D), ${ }^{1}$ Bahiru Bewket, ${ }^{2}$ and Shumet Getahun ${ }^{3}$ \\ ${ }^{1}$ Debre Tabor University, Faculty of Technology, Department of Civil Engineering (Construction Technology and Management), \\ Debre Tabor, Ethiopia \\ ${ }^{2}$ Adama Science \& Technology UniversityAdama, Adama, Ethiopia \\ ${ }^{3}$ Bahir Dar Institute of Technology, Faculty of Civil and Water Resource Engineering, Bahir Dar, Ethiopia \\ Correspondence should be addressed to Gashaw Abebaw; gashabe@dtu.edu.et
}

Received 22 October 2021; Revised 25 November 2021; Accepted 2 December 2021; Published 28 December 2021

Academic Editor: Bang Yeon Lee

Copyright (c) 2021 Gashaw Abebaw et al. This is an open access article distributed under the Creative Commons Attribution License, which permits unrestricted use, distribution, and reproduction in any medium, provided the original work is properly cited.

\begin{abstract}
Ethiopia's construction industry is aggressively expanding than ever before. Cement is the most essential and expensive material in this regard. Cement takes $10 \%-15 \%$ by volume of concrete. Nowadays, the construction industry is challenged by the scarcity of cement and price escalation of the cement market. However, scholars try to replace cement with pozzolanic material. Besides this, they investigated that bamboo leaf ash possesses pozzolanic properties. Ethiopia has about 850,000 hectares of lowland bamboo, so it is good to utilize bamboo leaf ash as a replacement material for cement. In this study, the capability of lowland Ethiopian bamboo leaf ash as a partial substitute for cement in C-25 concrete production with $0 \%, 5 \%, 10 \%, 15 \%$, and $20 \%$ replacement of OPC by BLA with 0.49 percent water-to-cement ratio was investigated. This study examines the chemical properties of BLA, physical properties of cement paste, workability, compressive strength, water absorption, density, and sulfate attack of concrete. The chemical composition of bamboo leaf ash was examined, the summation of $\mathrm{SiO}_{2}, \mathrm{AlO}_{3}$, and $\mathrm{FeO}_{3}$ is $76.35 \%$, and the ash was classified class $\mathrm{N}$ pozzolan. The normal consistency percentage of water increases as the BLA replacement amount increases, and both initial and final setting time ranges increase as the BLA replacement amount increases. The compressive strength of concrete for $5 \%$ and $10 \%$ BLA achieves the target mean strength $(33.5 \mathrm{MPa})$ on the 28 th day, and on the 56 th day, $5 \%$ and $10 \%$ replacements increase the concrete strength by $1.84 \%$ and $0.12 \%$, respectively. The water absorption and sulfate attack have significant improvement of the BLA-blended concrete on 5\% and 10\% BLA content. According to the findings, bamboo leaf ash potentially substitutes cement up to $10 \%$. The outcome of the study will balance the cement price escalation and increase housing affordability without compromise in quality.
\end{abstract}

\section{Introduction}

Concrete is a substance that is made up of several different components that contain a binding base where there are embedded particles or fragments of aggregates [1]. Concrete is composed of cement, aggregates, chemical admixtures, mineral admixtures, and water and encompasses all artificial materials in quantity. Concrete utilization on our planet Earth is in billions of tons. Thus, one million metric tons of $\mathrm{CO}_{2}$ are produced per annum due to cement consumption and production, which, in turn, causes environmental threats [2]. The manufacturing of portland cement is expensive with energy consumption at a very high temperature. The cement industry roughly emits $900 \mathrm{~kg}$ of $\mathrm{CO}_{2}$ every $1,000 \mathrm{~kg}$ of cement, with around $5 \%$ of all carbon dioxide emissions [3]. When manufacturing portland cement burning at a large rotary kiln at an approximate temperature of $1,400^{\circ} \mathrm{C}$, the amount of coal required to manufacture 1 (one) ton of cement is between $100 \mathrm{~kg}$ and about $350 \mathrm{~kg}$ [4]. Cement manufacturing needs much energy consumption and releases harmful gas to the environment, polluting the atmosphere. Partial cement replacement with locally available material will reduce the amount of energy and environmental impact. It is a good way to use 
agricultural waste, an industrial by-product, and plant residual in the designated position of portland cement to reduce the consumption of the raw materials, protect the environment, and enhance the quality of cement. Partial replacement of cement with waste material that has pozzolanic properties in concrete production is a worldwide practice [5]. Nowadays, some agricultural by-products and wastes are attracting much research because of their pozzolanic content for use as additives in commercial portland cement [6]. The performance of concrete is commonly improved due to the hydration phase during the pozzolanic reaction. Several research studies on the use of bamboo leaf ash (BLA) as a pozzolanic material in the making of concrete have been undertaken across the world. [7] investigated that the bamboo leaf ash is a good pozzolanic material that reacts with calcium hydroxide forming calcium silicate hydrate. The pozzolanic activity of bamboo leaf ash increases with the increase in time and temperature. [8] concluded that BLA can be used as a natural pozzolan to replace cement in concrete production. [9] investigated that for concrete grade M-20, from the results, the measured value of maximum load and compressive strength of $5 \%$ blended concrete was higher than that of OPC (0\%) concrete. But, only $5 \%$ and $10 \%$ blended concretes reached the target strength. However, nothing has been done, based on the findings, to investigate the viability of using Ethiopian BLA for this purpose. However, Ethiopia is gifted with huge bamboo resources. According to the records, Ethiopia has around 1 million hectares of bamboo forest, accounting for around 67 percent of African bamboo forest cover and 7\% of global bamboo forest cover [10]. The availability of bamboo, the low technology required to process it into ash, and its pozzolanic reaction necessitate its usage as a material for the production of some building elements for affordable housing provision, especially in developing countries. As a consequence, this study aims to find out how bamboo leaf ash mixed with cement affects the qualities of concrete. An experimental investigation will be carried out to examine the impact of partial replacement of BLA on the mechanical and physical properties of concretes such as consistency, setting time, workability, compressive strength microstructure, and durability.

\section{Materials}

2.1. Cement. For this study, ordinary portland cement (OPC), which is manufactured from a Dangote cement factory, was available at markets and tested according to the ASTM standards. Table 1 illustrates the physical properties of the cement, Figure 1.

2.2. Bamboo Leaf. The bamboo leaf used for this study was taken from Awi Zone, Ethiopia. One metric ton of bamboo leaf was collected from the source and then sun-dried, and it was burnt in an open environment before being burned in a furnace for two hours at $600^{\circ} \mathrm{C}$ in which it was found to be an amorphous material containing amorphous silica [7]. This is to remove extra carbon in the ash. Bamboo leaf ash is produced at the DTU Chemistry Department laboratory. After the bamboo leaf was burned, it was sieved through a $75 \mu \mathrm{m}$; the ash that remained was ground using a small mill machine found in Debre Tabor University's Faculty of Computing's mechanical unit operation laboratory. Physical and chemical compositions of BLA used for this study are as shown in Tables 2 and 3. The ASTM standard was used for physical property testing. The analytical methodologies are $\mathrm{LiBO}_{2}$, fusion, $\mathrm{HF}$ attack, gravimetric, colorimetric, and AAS. In November 2020, the Ethiopian Geological Survey's Geochemical Laboratory Directorate conducted the test. The fineness of the ash retained on $45 \mu \mathrm{m}$ (No. 325) sieve is $30.50 \%$, which is less than the maximum value of $34 \%$ specified by ASTMC 618.

2.3. Coarse Aggregate. For this study, the crushed aggregate of basaltic rock was used. The size of the maximum aggregate size is $25 \mathrm{~mm}$. The types and methods of tests are given in Table 4.

2.4. Fine Aggregate. For the sake of this specific study, river sand was used as a fine aggregate. The following tests and methods are conducted as given in Table 5.

2.5. Water. For this study, potable water available in the Faculty of Technology, Civil Engineering Construction Material Laboratory, Debre Tabor University, was used in all mixes and curing.

\section{Experimental Procedure}

3.1. Mix Design. In this specific study, the mix design of concrete with determined ratios of cement, sand, water, coarse aggregate, and BLA was proportioned for a C-25 concrete grade based on the ACI mix design method. The trail mix was organized for characteristic strength of $25 \mathrm{MPa}$, while the water-to-cement ratio was 0.49 and ordinary portland cement content was $365 \mathrm{~kg} / \mathrm{m}^{3}$. Table 6 shows the mix code designation for the proportioning.

3.2. Mix Proportioning. The mix proportion of concrete ingredients was performed following ACI $211.1 \mathrm{mix}$ design practice. A total of 72 cubes were prepared in five series of concrete mixes. These ratios were $0 \%, 5 \%, 10 \%, 15 \%$, and $20 \%$. Here, it was prepared as a control mix OPC without the addition of BLA, whereas the remaining four series of concrete mixes were prepared by partial replacement of OPC with different percentages of bamboo leaf ash. The water-tocement ratio of all the series of concrete mixes was kept constant at 0.49 . The summaries of the mix proportion of all series of concrete mixes are shown in Table 7.

3.3. Specimen Preparation. The following sampling methods were applied to this study. For each cement replacement percentage, three $150 \mathrm{~mm}$ x $150 \mathrm{~mm} \times 150 \mathrm{~mm}$ cube samples were produced with BLA replacement percentages of $0 \%$, $5 \%, 10 \%, 15 \%$, and $20 \%$. Concrete specimens were cast and 
TABLe 1: Cement properties.

\begin{tabular}{lccr}
\hline Properties & & Result & Test standard \\
\hline Soundness $(\mathrm{mm})$ & & 0.9 & ASTM C-151 \\
Setting time $(\mathrm{min})$ & Initial & 120 & ASTM C-191 \\
Consistency $(\%)$ & Final & 280 & ASTM C-191 \\
\hline
\end{tabular}

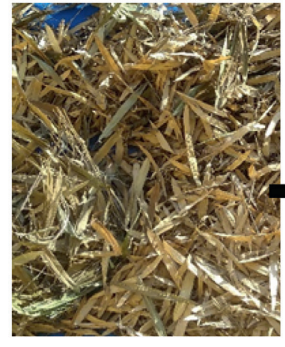

(a)

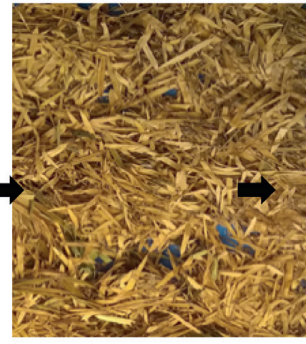

(b)

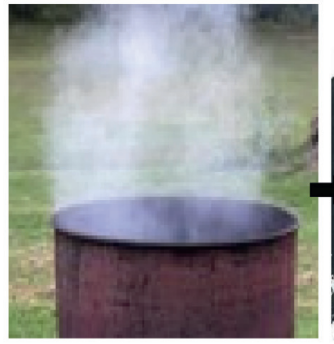

(c)

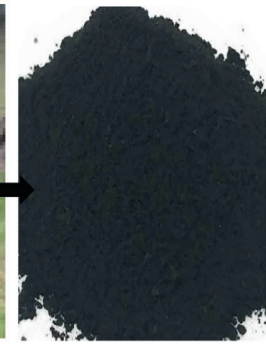

(d)

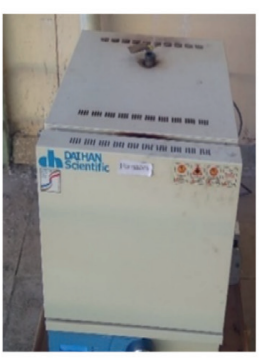

(e)

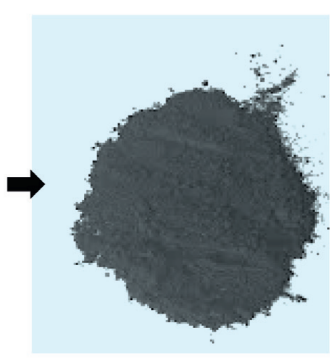

(f)

Figure 1: Bamboo leaf ash (BLA) preparation process. (a) Bamboo leaf. (b) Sun-dried bamboo leaf. (c) BL burning in the open air. (d) BLA from the open-air burning. (e) In the furnace, BLA is burning. (f) BLA from the furnace.

TABle 2: Chemical composition of BLA.

\begin{tabular}{lccccccccc}
\hline Oxide & $\mathrm{SiO}_{2}$ & $\mathrm{Al}_{2} \mathrm{O}_{3}$ & $\mathrm{Fe}_{2} \mathrm{O}_{3}$ & $\mathrm{CaO}$ & $\mathrm{MgO}$ & $\mathrm{Na}_{2} \mathrm{O}$ & $\mathrm{K}_{2} \mathrm{O}$ & $\mathrm{H}_{2} \mathrm{O}$ & $\mathrm{LoI}$ \\
\hline BLA composition & 65.66 & 6.41 & 4.28 & 15.22 & 2.48 & 2.76 & 4.84 & 1.03 & 9.65 \\
\hline
\end{tabular}

TABle 3: Physical properties of bamboo leaf ash.

\begin{tabular}{lc}
\hline Parameters & Result \\
\hline Color & Dark gray \\
Specific gravity & $2.15 \mathrm{~g} / \mathrm{cc}$ \\
Fineness & $30.50 \%$ \\
Density & $1217 \mathrm{~kg} / \mathrm{m}^{3}$ \\
\hline
\end{tabular}

TABLE 4: Physical properties of coarse aggregate.

\begin{tabular}{lccc}
\hline No. & Types of tests & Test result & $\begin{array}{c}\text { Test } \\
\text { standard }\end{array}$ \\
\hline 1. & Nominal maximum aggregate & $25 \mathrm{~mm}$ & ASTM-C33 \\
& size & $1611 \mathrm{~kg} /$ & ASTM-C29 \\
2. & Bulk unit weight & $\mathrm{m}^{3}$ & \\
3. & Specific gravity & 2.63 & ASTM-C127 \\
4. & Absorption & $1.41 \%$ & ASTM-C127 \\
5. & Moisture content & $0.53 \%$ & ASTM-C566 \\
\hline
\end{tabular}

TABle 5: Physical properties of fine aggregate.

\begin{tabular}{lccc}
\hline No. & Types of tests & Test result & Test standard \\
\hline 1. & Fineness modulus & 2.93 & ASTM-C136 \\
2. & Bulk unit weight & $1820 \mathrm{~kg} / \mathrm{m}^{3}$ & ASTM-C29 \\
3. & Specific gravity & 2.75 & ASTM-C128 \\
4. & Absorption & $2.1 \%$ & ASTM-C128 \\
5. & Moisture content & $1.03 \%$ & ASTM-C566 \\
\hline
\end{tabular}

TABle 6: Mix code designation.

\begin{tabular}{lcc}
\hline No. & Mix code & \multicolumn{1}{c}{ Description } \\
\hline 1. & Control OPC or BLA0 & Control mix or no addition of BLA \\
2. & BLA5 & $5 \%$ replacement of cement by BLA \\
3. & BLA10 & $10 \%$ replacement of cement by BLA \\
4. & BLA15 & $15 \%$ replacement of cement by BLA \\
5. & BLA20 & $20 \%$ replacement of cement by BLA \\
\hline
\end{tabular}


cured in the open tank for 3rd, 7th, 28th, and 56th days having 3 cube specimens for each duration and mix type. The concrete specimens with a total of 12 cubes were cured in the open tank for 7 days and kept in the open environment for 2 days, and then, the specimen is weighed and immersed in 5\% $\mathrm{Na}_{2} . \mathrm{SO}_{4}$ solution for 56 days to test the sulfate attack. A total of 12 cubes were cured in a tank for 28 days and then checked the water absorption of the concrete cube for each percentage replacement.

3.4. Testing of Specimens. The slump test is carried out as per the procedures mentioned in ASTM C143. ASTM 143 reports that the slump value is measured in terms of inch (millimeters) to the nearest $1 / 4$ inches $(5 \mathrm{~mm})$ of subsidence of the specimen during the test. The compressive strength test of concrete was conducted on a concrete cube of $150 \mathrm{~mm} \times 150 \mathrm{~mm} \times 150 \mathrm{~mm}$ on 3rd, 7th, 28th, and 56th days using a compressive strength testing machine, which has a maximum capacity of $2,000 \mathrm{KN}$. The average compressive strength of the three specimens was the strength value.

In this study, the durability of concrete will be examined by water absorption and sulfate attack. To examine the sulfate attack, the casted concrete cubes are soaked in 5\% $\mathrm{Na}_{2} \mathrm{SO}_{4}$ solution to examine the sulfate attack (durability) through testing the compressive strength of concrete before and after soaking into solution. While the minimum distance between the cubes was at least $25 \mathrm{~mm}$, the casted cube specimens were placed in the oven; the specimen was dried in the oven in which the temperature was controlled at $110^{\circ} \mathrm{C}$ for 72 hours. The dried specimen was cooled for $24 \mathrm{hrs}$, before measuring the weight of the specimens. Subsequently, the dried specimen was soaked in water for $24 \mathrm{hrs}$. Next to this, the specimen was removed from the water and the weight of the specimen was again measured. The water absorption of the specimens was determined to know the water absorption capacity and durability of concrete.

BS 1881: Part 122 states that the absorption test shall be performed when the age of the concrete is from 28 days to 32 days. The drying of concrete specimens shall begin at an age of 24 days to 28 days. For this study, 28th-day concrete specimens were selected for the water absorption test. The sulfate attack test shall be made when the age of concrete is 56 days. The water absorption, expressed in percentage, was then computed using the following equation [11].

$$
\text { water absorbition in (\%) }=\frac{M_{w}-M_{d}}{M_{d}},
$$

where $M_{w}$ is the mass of wet specimen after immersion in water for 72 hours, and $M_{d}$ is the mass of oven-dried specimen before immersion in water.

\section{Results and Discussion}

4.1. Slump Tests. One of the most essential qualities of fresh concrete is its workability. The slump test is the simplest workability test for concrete, due to its low cost, and also provides immediate results. Concrete should be workable enough to cast, consolidate, and finish; therefore, in all types of mixes slump tests were performed to determine the workability of freshly mixed concrete. The Ethiopian standard makes no mention of a workability test. The slump test is carried out as per the procedures mentioned in ASTM C143. ASTM 143 reports that the slump value is measured in terms of inch (millimeters) to the nearest $1 / 4$ inches $(5 \mathrm{~mm})$ of subsidence of the specimen during the test. The summaries of the slump test results are as shown in Table 8 below.

As shown in Table 8, as the replacement percentage of BLA increases, the slump value goes down. Therefore, the probable reason was due to the fineness of BLA and their large specific surface area though all other factors are constant [12]. Finer particle requires more water to wet their larger specific surface area. But up to $10 \%$ replacement level, the slump is still in the estimated range of $25 \mathrm{~mm}$ to $50 \mathrm{~mm}$.

4.2. Dry Density. The density of hardened concrete is determined based on the volume and the weight of the concrete cube. However, the weight of the specimens was measured just before the compressive strength testing was conducted. Here, the density of concrete specimens is calculated by using the 28th-day weight and the result is as shown below in Table 9.

Referring to Table 9, the density of concrete decreased as the percentage of BLA replacement levels increased. The probable reason is that the specific gravity of Dangote OPC cement (3.15) is higher than bamboo leaf ash with a specific gravity of 2.15, and referring back to section Physical Properties of BLA, unit weight is $1,217 \mathrm{~kg} / \mathrm{m} 3$ that is lighter than OPC cement of $1,400 \mathrm{~kg} / \mathrm{m} 3$. The density reduction shown in this table is for the 28th day. Here, the density reduction is compared with the reference mix of OPC control with BLA5, BLA10, BLA15, and BLA20; therefore, the density reduction is $0.25,0.89,1.67$, and 2.06, respectively.

Based on the results shown in Table 9, there is a major reduction in density, while the percentage of BLA replacement level is raised. The reduction in concrete density is an important property of concrete to build high-rise buildings, consequently, suitable for lightweight concrete construction. Therefore, the replacement of cement with BLA is very important to construct economical buildings and reduce building failures (settlement) due to heavy selfweight. The density of hardened concrete obtained from this study obtained similar results when compared with those of the studies of [13-15].

4.3. Compressive Strength. The compressive strength test of concrete is the main test conducted on the properties of hardened concrete. Here, the test was performed for all of the concrete cubes on the $3 \mathrm{rd}, 7 \mathrm{th}, 28 \mathrm{th}$, and 56th days after the casting date using a compression testing machine. For each of the results, the average values of three cubes were taken as their compressive strength. The overall compressive strength test result for all of the concrete cubes is as shown in Figure 2 below. 
TABLE 7: Mix proportion summery.

\begin{tabular}{|c|c|c|c|c|c|c|c|}
\hline \multirow{2}{*}{ Mix designation } & \multirow{2}{*}{ BLA\% (\%) } & \multicolumn{5}{|c|}{ Quantity of material per cubic meter $\left(\mathrm{kg} / \mathrm{m}^{3}\right)$} & \multirow{2}{*}{$\mathrm{W} / \mathrm{C}$ ratic } \\
\hline & & Cement & BLA & Water & Fine agg & Coarse agg & \\
\hline OPC C & 0 & 365 & 0 & 196.74 & 778 & 1086 & 0.49 \\
\hline BLA5 & 5 & 346.5 & 18.25 & 196.74 & 778 & 1086 & 0.49 \\
\hline BLA10 & 10 & 328.5 & 36.5 & 196.44 & 778 & 1086 & 0.49 \\
\hline BLA15 & 15 & 310.25 & 54.75 & 196.44 & 742.15 & 1086 & 0.49 \\
\hline BLA20 & 20 & 292 & 73 & 196.44 & 739.75 & 1086 & 0.49 \\
\hline
\end{tabular}

$\mathrm{BLA}=$ Bamboo leaf ash $\mathrm{W} / \mathrm{C}=$ water-to-cement ratio.

TABLE 8: Slump value.

\begin{tabular}{lccc}
\hline S. no & Mix code & W/C ratio & Observed slump (mm) \\
\hline 1 & Control OPC & 0.49 & 30 \\
2 & BLA5 & 0.49 & 25 \\
3 & BLA10 & 0.49 & 25 \\
4 & BLA15 & 0.49 & 20 \\
5 & BLA20 & 0.49 & 20 \\
\hline
\end{tabular}

TABLE 9: Density of hardened concrete.

\begin{tabular}{lcc}
\hline Mix code & The density of hardened concrete on the 28th day & Reduction (\%) \\
\hline Control OPC & 2389 & 0.00 \\
BLA5\% & 2383 & 0.25 \\
BLA10\% & 2368 & 0.89 \\
BLA15\% & 2350 & 1.67 \\
BLA20\% & 2341 & 2.06 \\
\hline
\end{tabular}

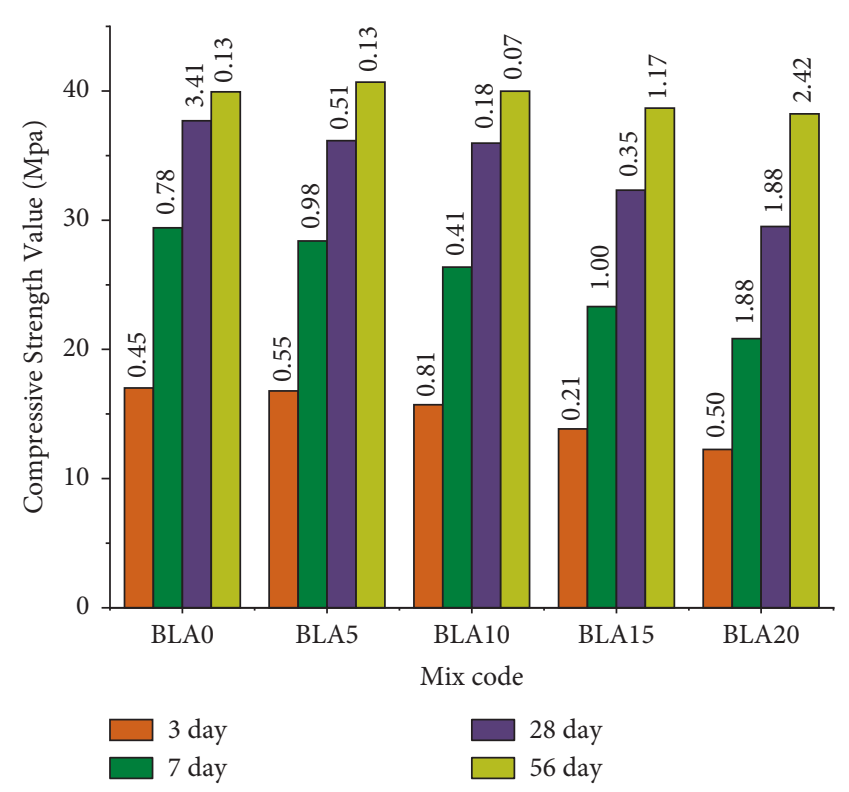

FIGURE 2: Compressive strength results for 3rd, 7th, 28th, and 56th days.

From Table 10, the compressive strength of concrete was checked taking bamboo leaf ash (BLA) as a partial replacement for cement up to $10 \%$, and the OPC control achieved the target mean strength of $33.5 \mathrm{Mpa}$ after 28 days; however, the mix designations for BLA15\% and BLA20\% did not. However, the compressive strength values of BLA15\% and BLA20\% were $30.47 \mathrm{MPa}$ and $27.88 \mathrm{MPa}$, respectively, and they attain the characteristic strength of $25 \mathrm{MPa}$ on the 28th day.

From Table 10, BLA5\%, BLA10\%, BLA15\%, and BLA20\% had shown the compressive strength reduction by $4.27 \%, 4.86 \%, 16.65 \%$, and $27.76 \%$ respectively, as compared to the OPC control mix on the 28th day. This indicates that the compressive strength of BLA-blended concrete decreases with an increase in BLA content. The reason for compressive strength reduction is due to the high replacement of BLA and cement content reduction per cubic meter of concrete by $5 \%, 10 \%, 15 \%$, and $20 \%$ from the normal concrete mix, also the pozzolanic reaction takes a long time, and this leads to compressive strength reduction [16].

The compressive strength of normal concrete and concrete blended with BLA at the curing age of 3rd, 7th, 28th, and 56th days is displayed in Figure 2. It can be observed that BLA as a partial substitute for cement up to $10 \%$ and OPC control meet the goal mean strength of $33.5 \mathrm{Mpa}$ at 28 days, but the mix designations for BLA15\% and BLA20\% did not. However, the compressive strength values of BLA $15 \%$ and BLA20\% were $32.32 \mathrm{MPa}$ and $29.51 \mathrm{MPa}$, respectively, and they attain the characteristic strength of 25 Mpa on the 28th day. There was also a subsequent strength increase at 56 days for percentage replacement from $5 \%$ to $10 \%$ replacement and a decline in strength at $15 \%$ and $20 \%$ replacements as compared to the reference mix. The average compressive strength value of $5 \%$ and $10 \%$ BLA on the 56 th 
TABLE 10: Compressive strength reduction and increment value.

\begin{tabular}{|c|c|c|c|c|c|}
\hline Mix code & Control OPC & BLA5 & BLA10 & BLA15 & BLA20 \\
\hline 28th-day compressive strength $(\mathrm{MPa})$ & 37.70 & 36.16 & 35.96 & 32.32 & 29.51 \\
\hline Reduction (\%) & 0.00 & 4.27 & 4.86 & 16.65 & 27.76 \\
\hline 56th-day compressive strength $(\mathrm{MPa})$ & 39.93 & 40.68 & 39.98 & 38.68 & 38.23 \\
\hline Increments $(\%)$ & 0.00 & 1.84 & 0.12 & -3.24 & -4.45 \\
\hline
\end{tabular}

day were $40.68 \mathrm{MPa}$ and $39.98 \mathrm{MPa}$, respectively, which is greater than the control mix $(39.93 \mathrm{MPa})$. It is because BLA has more silicon dioxide than OPC, and calcium silicate hydrate (C-S-H) develops over long hydration times [7]. The data on top of the bar chart are the standard deviation of compressive strength.

Referring to Table 10, the percentage increase at 56 th day compressive strength test relative to the control sample at 5\% and $10 \%$ replacements was $1.84 \%$ and $0.12 \%$, while the percentage decrease at $15 \%$ and $20 \%$ BLA replacements relative to the control sample was by $3.24 \%$ and $4.45 \%$. The increase in strength could be a result of the presence of a high amount of silica (SiO2) 65.66\% in the ash and the amount of $\mathrm{CaO}$ is $15.22 \%$ which was responsible for the formation of tricalcium silicate and dicalcium silicate which both do oxidize with water to form a C-H-S bond (calcium silicate hydrate) which was the determining factor for strength gain [1]. The optimum strength was recorded at $10 \% \mathrm{BLA}$ replacement at 56th day curing age. It could be that C-S-H is most effective at $10 \%$ BLA replacement. The compressive strength obtained from this study found better results when compared with those of earlier studies [13-15].

Referring to Table 11 and Figure 2, for all concrete mixtures of BLA with their respective curing ages, the mean standard deviation is less than $15 \%$. The concrete mix was performed according to the mix design procedures and techniques as per validity analysis.

The degree to which the results of a measure (experimental work) accurately reflect the variable for which they were designed is known as validity. The mean compressive strength of concrete for each specimen and the curing age were the main experimental work (test) variables in this study. This variable was validated by comparing it to the designrequired target mean strength and analyzing the standard deviation between concrete cube specimens for each curing duration. Concrete's compressive strength increases with curing time. One method for determining the validity of the mean compressive strength test results is to use the standard deviation of the concrete cube specimen. If the individual variation is less than $15 \%$ of the average, the average of three specimen values shall be taken as representative of the batch, according to Indian Standard, 2006. There is no detailed information about this in any Ethiopian concrete standard.

4.4. Water Absorption. The overall water absorption test result for all of the concrete cubes is as shown in Table 12 below.

Referring to Table 12, the water absorption of BLAblended cement concrete cubes is shown. A general BLA10\% water absorption is higher than control OPC and then starts
TABLE 11: Mean standard deviation from the compressive strength average value.

\begin{tabular}{lcccc}
\hline \multirow{2}{*}{ Mix code } & \multicolumn{4}{c}{ Mean standard deviation value (\%) } \\
& 3rd day & 7th day & 28th day & 56th day \\
\hline Control OPC & 0.45 & 0.78 & 3.41 & 0.13 \\
BLA5\% & 0.55 & 0.98 & 0.51 & 0.13 \\
BLA10\% & 0.81 & 0.41 & 0.18 & 0.07 \\
BLA15\% & 0.21 & 1.00 & 0.35 & 1.17 \\
BLA20\% & 0.50 & 1.88 & 1.88 & 2.42 \\
\hline
\end{tabular}

TABLE 12: Water absorption of BLA-blended cement concrete.

\begin{tabular}{lc}
\hline Mix code & Water absorption $(\%)$ \\
\hline Control OPC & 3.00 \\
BLA5\% & 2.9 \\
BLA10\% & 3.1 \\
BLA15\% & 3.2 \\
BLA20\% & 3.6 \\
\hline
\end{tabular}

increasing from $15 \%$ to $20 \%$. The percentage water absorption ranges between $2.9 \%$ and $3.6 \%$ with the least value attained at $5 \%$ BLA $(2.90 \%)$ content, and the greatest value of $3.6 \%$ is attained at $20 \%$ BLA content on the 28 th day. The water absorption of the $5 \%$ and $10 \%$ BLA-blended cement concrete specimens did not have much water absorption as the reference, which is an indication of the integration of BLA in the voids thereby causing impermeability. The decrease in water absorbed at lower BLA replacement is also qualified to the initial filling of the voids by the BLA ingredient. The decrease in water absorbed at lower BLA replacement may be attributed to the initial filling of the voids by the incorporated BLA [11]. However, at higher levels of BLA substitution, there was an insufficient quantity of calcium hydroxide to react with the excess BLA, thus creating pores in the mixture and thereby increasing the water absorption. This finding agrees with previous observations by $[11,14]$.

4.5. Sulfate Attack Analysis. The effect of BLA replacement on sulfate resistance was examined after 56 days of curing age. The BLA-blended concrete sulfate resistance result is expressed in terms of compressive strength loss. The result is presented in Figure 3 below.

The compressive strength loss due to sodium sulfate attack after immersing the specimens for 56 days in the $5 \%$ sodium sulfate solution for the control mix (BLA0\%) was assessed as $4.58 \%$. As referring to Figure 3, the BLA-blended mix, BLA5\%, BLA10\%, BLA15\%, and BLA20\% suffered $3.37 \%, 3.93 \%, 4.63 \%$, and $4.79 \%$ strength loss at their age of 


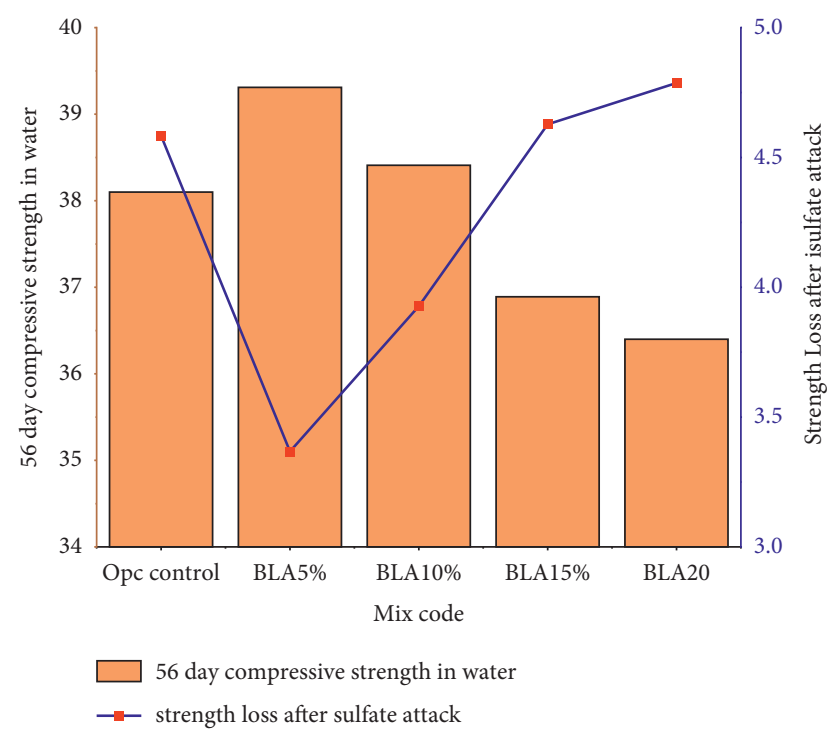

FIgURE 3: Strength loss due to sodium sulfate $\left(\mathrm{Na}_{2} \mathrm{SO}_{4}\right)$ attack.

56th day. Maximum strength loss was experienced in BLA $20 \%$, whereas minimum loss was noticed in BLA5\%. Loss of strength increased with BLA as the replacement amount increased. But, BLA10\% strength loss is higher than control OPC loss of strength that increased with BLA content. Sodium sulfate reacts with calcium hydroxide and hydrated calcium aluminates. It completely decomposes the hydrated calcium silicates and makes the concrete a friable mass $[17,18]$. Resistance to sulfate attack is found more in concrete made with $5 \%$ and $10 \%$ bamboo leaf ash due to a rise in homogeneity and decrease in sorptivity [19]. The result obtained from this study found better results when compared with those of the study by [20]. According to [20], investigation of OPC/BLA-blended cement concrete at $10 \%$ replacement was performed better in $\mathrm{Na}_{2} \mathrm{SO}_{4}$ solution over that of OPC concrete cured in the same medium solution at 56 th-day curing age. The OPC concrete in $\mathrm{Na}_{2} \mathrm{SO}_{4}$ solution shows signs of strength loss from 23.64 to 21.82 .

4.6. Regression and Correlation. In regression analysis, the value of at least one independent variable is used to predict the value of a dependent variable. It explains how changes in an independent variable influence the dependent variable. The dependent variable in this case was compressive strength, while the independent variable was density. Origin Pro 2021 was used to simultaneously calculate the linear regression equation and correlation. The degree of association (linear relationship) between two variables is determined using correlation analysis. It is all about how strong the relationship between variables is. The sample correlation coefficient " $r$ " is a measure of the strength of the linear relationship between the sample observations. Pearson's correlation coefficient $(r)$ is unit free; it ranges between -1 and 1 . Hence, -1 is a negative relationship, 0 is the weaker or no relationship, and 1 is a positive linear relationship [21].
4.6.1. Density and Compressive Strength. It is drafted as a linear equation with two variables $(X$ and $Y$ ). For three cube specimens, $X$ is the average density of concrete. Under various BLA additions, $Y$ represents the average compressive strength of concrete. The sample correlation coefficient is a measurement of the strength of the linear relationship between the experimental results.

Figure 4 shows that the compressive strength of concrete increases with curing age as the density of the concrete increases. It demonstrates that the compressive strength and density of concrete are directly proportional variables. The 28th-day compressive strength has a significant positive correlation (0.960) as related to the 28th-day concrete density, as shown in Figure 5. In line with this, as stated in the previous sections, Pearson's correlation coefficient $(r)$ is between -1 and +1 . Based on this, the correlation coefficient is +0.960 , which is a nearly positive one, arguing that the 28th-day compressive strength and 28th-day density have a direct relationship.

According to Figure 6, the compressive strength of concrete increases as the density decreases for the control mix, 5\% BLA replacement, and 10\% BLA replacement but decreases for the other mixes as the density decreases on the 56th-day curing age of concrete. On the 56th day of curing, Table 4 shows that the compressive strength of concrete decreases as the density of the concrete decreases. It demonstrates that concrete compressive strength and density are proportional variables for $15 \%$ and $20 \%$ BLA replacement. The coefficient of correlation between the 56th-day compressive strength and the 56 th concrete density is 0.343 . This result agreed with the previous regression analysis. Referring to Figure 6, the compressive strength of concrete increases as density decreases for the control mix, 5\% BLA replacement, and $10 \%$ BLA replacement at the 56th-day curing age. This explains why there is less correlation between compressive strength and density at the 56th-day curing age.

4.6.2. Water Absorption and Compressive Strength. The sample correlation coefficient is a measurement of the strength of the linear relationship between the experimental outcome and the sample correlation coefficient. The average of all mix compressive strength and water absorption value at the 28th-day curing age was used to calculate the correlation. The formula is a two-variable linear equation $(X$ and $Y$ ). For three cube samples, $X$ represents the average water absorption of curing concrete on the 28th day, and $Y$ represents the average compressive strength of concrete at various BLA replacement levels.

The regression graph of Figure 7 demonstrates that the compressive strength of concrete decreases as the water absorption of the concrete increases. It demonstrates that the compressive strength and water absorption of concrete are inversely proportional variables. The 28 th-day compressive strength has a significant negative correlation $(-0.931)$ with the 28th-day water absorption (\%). This correlation analysis shows that water absorption and concrete compressive strength had a negatively strong relationship. Accordingly, 


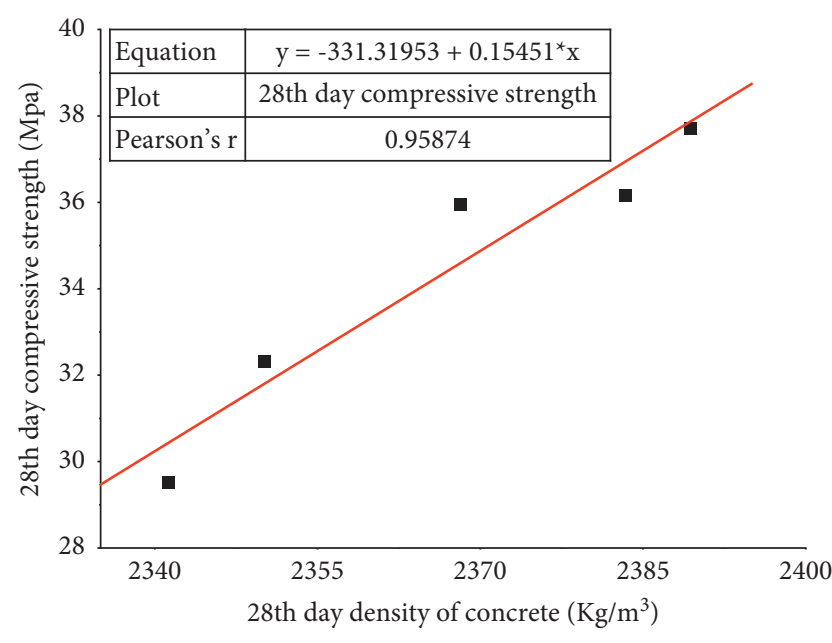

FIGURE 4: Compressive strength and density regression at 28 days.

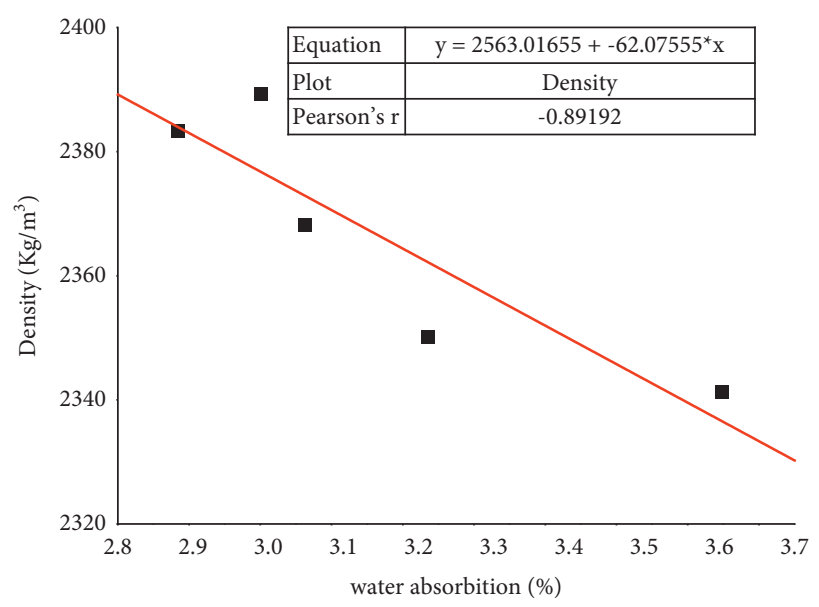

FIGURE 5: Regression analyses of concrete density and water absorption.

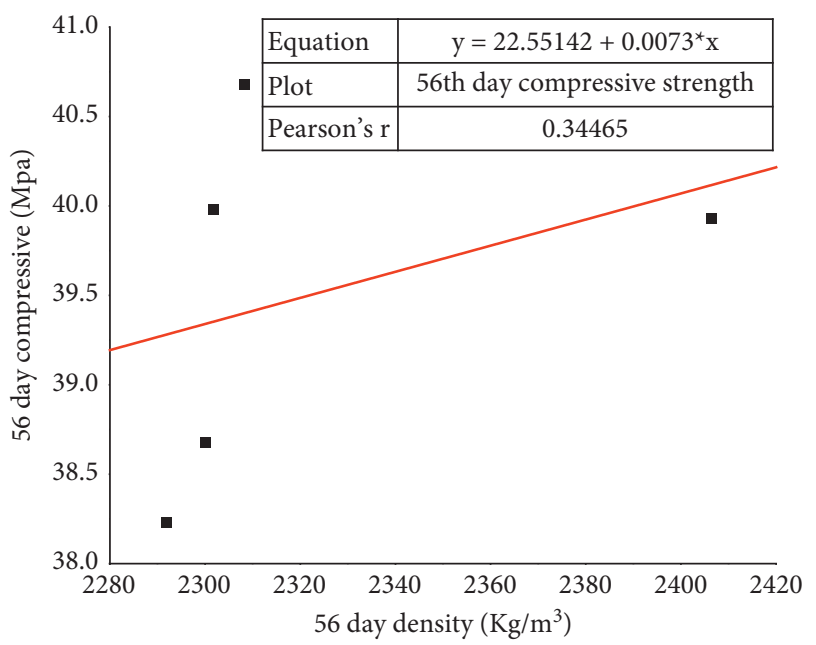

FIGURE 6: Compressive strength and density regression at 56 days.

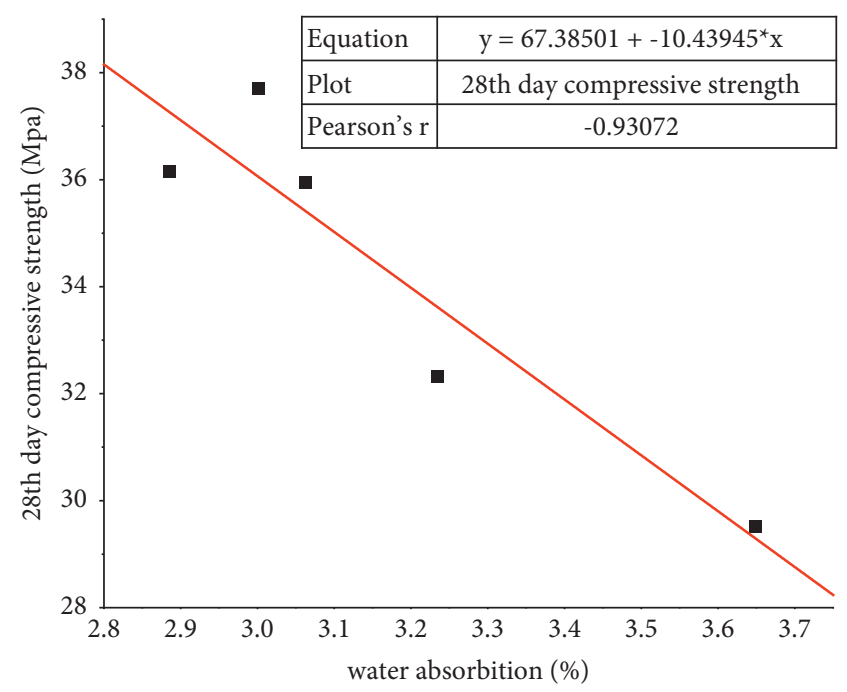

FIGURE 7: Compressive strength and water absorption regression.

this study proved that as water absorption percent increases the compressive strength decreases.

4.6.3. Water Absorption and Density of Concrete. The correlation was calculated using the average of all mix density and water absorption values at the 28th-day curing age. The formula is a two-variable linear equation ( $X$ and $Y$ ). For three cube samples, the average water absorption of 28th-day cured concrete is $X$ and $Y$ represents the average density of concrete at various BLA replacement levels.

According to the regression analysis illustrated in Figure 5 , the density of concrete decreases as the water absorption of the concrete increases. It indicates that concrete water absorption and density are inversely proportional variables. Referring to Figure 5, the 28th-day concrete density has a substantial negative connection (-0.892) with the 28th-day water absorption percentage. According to this correlation finding, there is a negative link between water absorption and concrete density. As a result, the study demonstrated that as the percentage of water absorption increases, the density decreases.

\section{Conclusions}

BLA was utilized as a cement-substituting material on concrete production based on experimental investigation, from which the following conclusion was derived. The workability of concrete decreases as the BLA replacement amount increases, but the setting time, water percentage for consistency, and soundness of cement paste all increase. On the 28th day, the compressive strength of concrete made with partial replacement of cement by up to $10 \%$ attains the target mean strength $(33.5 \mathrm{MPa})$, and there are $1.84 \%$ and $0.12 \%$ enhancements in compressive strength values for $5 \%$ and $10 \%$ replacements compared to the control mix on the 56th day, while the density reduced as the BLA replacement increased. The water absorption of the BLA-blended 
concrete was lower than the reference at 5\% and $10 \%$ BLA content, and the BLA-blended concrete showed significant sulfate attack resistance, particularly when compared to the reference. Based on the study of compressive strength and durability (water absorption and sulfate attack), 10\% replacement of cement by BLA is the optimum percentage for obtaining maximum strength values.

\section{Data Availability}

The experimental data used to support the findings of this study are available from the corresponding author upon request.

\section{Conflicts of Interest}

The authors declare that there are no conflicts of interest.

\section{References}

[1] Z Li, Advanced Concrete Technology, John Wiley \& Sons, Hoboken, NJ, USA, 2011, https://www.wiley.com/go/ permissions.

[2] A. Baikerikar, "A review on concept of sustainable concrete," in Proceedings of the Recent Advances in Civil Engineering 2018 (RACE-2018), Chikodi, India, March 2018.

[3] M. Ba-Shammak, H. Caruso, A. Elkamel, E. Croiset, and P. L. Douglas, "Analysis and optimization of carbon dioxide emission mitigation options in the cement industry," American Journal of Environmental Sciences, vol. 4, no. 5, pp. 482-490, 2008, https://doi.org/10.3844/ajessp.2008.482. 490.

[4] A. M. Neville and J. B. J, Concrete Technology, Pearson Education Limited, London, UK, 2nd edition, 2010.

[5] R. Walker and S. Pavía, "Physical properties and reactivity of pozzolans, and their influence on the properties of limepozzolan pastes," Materials Structures, vol. 44, no. 6, pp. 1139-1150, 2011, https://doi.org/10.1617/s11527-0109689-2.

[6] S. C. Paul, P. B. K. Mbewe, S. Y. Kong, and B. Savija, "Agricultural solid waste as source of supplementary cementitious materials in developing countries," Materials (Basel), vol. 12, no. 7, 2019.

[7] V. N. Dwivedi, N. P. Singh, S. S. Das, and N. B. Singh, "A new pozzolanic material for cement industry: bamboo leaf ash," International Journal of Physical Science, vol. 1, no. 3, pp. 106-111, 2006.

[8] G. Dhinakaran and G. H. Chandana, "Compressive strength and durability of bamboo leaf ash concrete," Jordan Journal of Civil Engineering, vol. 10, no. 3, pp. 279-289, 2016.

[9] A. Thandar, M. Wai, A. T. Oo, and Y. M. Maung, "Feasibility study of bamboo ash on concrete," Journal of MyanmarAcademic of Arts and Science, vol. XVII, no. 2, 2019.

[10] Y. M. A. A. Z. Tadesse, Bamboo Species Biological, Ecological And Management Aspects Bamboo Species, Ethiopian Environment and Forest Research Institute, Addis Ababa, Ethiopia, 2016.

[11] A. A. Umoh and A. O. Ujene, "Empirical study on effect of bamboo leaf ash in concrete," Journal of Engineering and Technology, vol. 5, no. 2, pp. 71-82, 2014.

[12] S. A. Ademola and T. A. Buari, "Behaviour of bamboo leaf ash blended cement concrete in sulphates environment," IOSR Journal of Engineering (IOSRJEN), vol. 4, no. 6, pp. 1-8, 2014.
[13] A. Olutogef and O. M. Oladunmoye, "Bamboo leaf ash as supplementary cementitious material," American Journal of Engineering Research (AJER), vol. 6, pp. 1-8, 2017.

[14] O. Onikeku, S. M. Shitote, J. Mwero, and A. A. Adedeji, "The open construction \& building," Evaluation Of Characteristics Of Concrete Mixed With Bamboo Leaf Ash Abstract, vol. 13, pp. 67-80, 2019.

[15] T. T. Hnin, K. L. Htet, N. N. M. Kyaw, and M. Kyaw, "Experimental investigation on effect of bamboo leaf ash replacing cement on compressive strength," International Journal of Science and Engineering Applications, vol. 7, no. 10, pp. 406-410, 2018.

[16] M. J. Mccarthy and T. D. Dyer, "Pozzolanas and pozzolanic materials," in Leas Chemistry of Cement and Concrete, Elsevier, Amsterdam, Netherlands, 5th editionhttps://doi.org/ 10.1016/B978-0-08-100773-0.00009-5, 2019.

[17] B. Mather, "Concrete durability," Cement and Concrete Composites, vol. 26, no. 1, pp. 3-4, 2004.

[18] P. K. Acharya and S. K. Patro, "Acid resistance, sulphate resistance and strength properties of concrete containing ferrochrome ash (FA) and lime," Construction and Building Materials, vol. 120, pp. 241-250, 2016, https://doi.org/10.1016/ j.conbuildmat.2016.05.099.

[19] K. J. Temitope and O. K. Olubunmi, "Durability of ternary blended cement concrete containining bamboo leaf ash and pulverized burnt clay," Civil and Environmental Research, vol. 8, no. 1, pp. 57-64, 2015, https://doi.org/10.13140/RG.2.2. 27140.22404 .

[20] S. A. Ademola and T. A. Buari, "Behaviour of bamboo leaf ash blended cement concrete in sulphates environment," structures and materials engineering, vol. 4, no. 6, pp. 1-8, 2014.

[21] K. Stapor, "Linear regression and correlation," Intelligent Systems Reference Library, vol. 176, pp. 133-149, 2020, https://doi.org/10.1007/978-3-030-45799-0_3. 